\title{
Fórum MUNDiAL DE EDUCAÇÃo SÃo PAUlo
}

O Comitê Organizador do Fórum Mundial de Educação (FME-SP) convida entidades, instituições e profissionais de todas as áreas, aqui, em especial, os arquitetos, engenheiros e urbanistas, a integrarem este movimento em prol da educação. O FME-SP, cujo tema central é Educação cidadã para uma cidade educadora, será realizado de 1ㅇ a 4 de abril, compondo o calendário de eventos comemorativos dos 450 anos da grande metrópole, São Paulo, para os quais se estima uma participação superior a 60.000 pessoas.

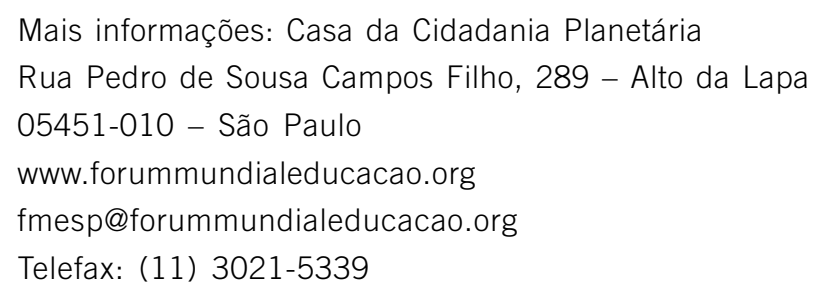

No texto seguinte, o Prof. Dr. Moacir Gadotti fornece subsídios para uma maior compreensão desse movimento de caráter mundial, que vem acontecendo no Brasil desde 2001.

\section{ESCOLA CIDADÃ, CIDADE EDUCADORA PROJETOS E PRÁTICAS EM PROCESSO}

\section{Moacir Gadotti}

A relação entre escola cidadã e cidade educadora encontra-se na própria origem etimológica das palavras cidade e cidadão. Ambas derivam da mesma palavra latina, civis, cidadão, membro livre de uma cidade a que pertence por origem ou adoção, portanto, sujeito de um lugar, aquele que se apropriou de um espaço, de um lugar. Assim, cidade (civitas) é uma comunidade política cujos membros, os cidadãos, autogovernam-se e cidadão é a pessoa que goza do direito de cidade. Cidade, cidadão, cidadania se referem a uma certa concepção da vida das pessoas, daquelas que vivem de forma "civilizada" (de civilitas, afabilidade, bondade, cortesia), participando de um mesmo território, autogovernando-se, construindo uma "civilização". É claro que, em Roma, esse conceito de sujeito da 
(1) Uma experiência muito próxima foi a realizada nos Estados Unidos pelo educador popular Myles Horton com as chamadas citizenship schools. Paulo Freire e Myles Horton, no livro We make the road by walking (1990), discutem essa experiência baseada na conquista dos direitos civis que ambos vivenciaram. Tanto um quanto outro, com histórias paralelas e semelhantes, influenciaram os sistemas de ensino com base no princípio da cidadania.

(2) GADOTTI, Moacir. Escola cidadã: Uma aula sobre a autonomia da escola. São Paulo: Cortez, 1992.

(3) FREIRE, Paulo. Pedagogia da autonomia. São Paulo: Cortez, 1997, p. 66. cidade era limitado apenas a poucos homens livres, cuja cultura era o reflexo do ócio e não do trabalho. O trabalho era reservado a numerosos escravos. Esses eram sujeitos "sujeitados", submetidos e, portanto, não eram considerados cidadãos, não tinham os direitos de cidadania, não eram considerados civilizados, mas estrangeiros, bárbaros, não podendo usufruir dos benefícios da civilização.

Da origem das palavras na Antiguidade, passemos aos fatos que hoje designam o que chamamos escola cidadã e cidade educadora.

A idéia e o projeto de uma escola cidadã nasceram, no Brasil ${ }^{1}$, no final da década de 80 e início da década de 90², fortemente enraizados no movimento de educação popular e comunitária o qual, na década de 80, traduziu-se pela expressão "escola pública popular". Designa-se, comumente, por "Escola Cidadã", uma certa concepção e uma certa prática da educação "para e pela cidadania", que, sob diferentes denominações, são realizadas, em diversas regiões do país, principalmente em municipalidades nas quais o poder local foi assumido por partidos do chamado campo democrático-popular.

A maior ambição da escola cidadã é contribuir na criação das condições para o surgimento de uma nova cidadania, como espaço de organização da sociedade para a defesa de direitos e a conquista de novos. Trata-se de formar, para a gestação de um novo espaço público não-estatal, uma "esfera pública cidadã" (Jürgen Habermas), que leve a sociedade a ter voz ativa na formulação das políticas públicas, visando a uma mudança do Estado que temos para um Estado radicalmente democrático.

Foi Paulo Freire quem melhor definiu uma educação para e pela cidadania quando, nos Arquivos Paulo Freire, em São Paulo, dia 19 de março de 1997, em uma entrevista à TV Educativa do Rio de Janeiro, falou de sua concepção da escola cidadã: "A Escola Cidadã é aquela que se assume como um centro de direitos e de deveres. O que a caracteriza é a formação para a cidadania. A Escola Cidadã, então, é a escola que viabiliza a cidadania de quem está nela e de quem vem a ela. Ela não pode ser uma escola cidadã em si e para si. Ela é cidadã na medida mesma em que se exercita na construção da cidadania de quem usa o seu espaço. A Escola Cidadã é uma escola coerente com a liberdade. É coerente com o seu discurso formador, libertador. É toda escola que, brigando para ser ela mesma, luta para que os educandos-educadores também sejam eles mesmos. E como ninguém pode ser só, a Escola Cidadã é uma escola de comunidade, de companheirismo. É uma escola de produção comum do saber e da liberdade. É uma escola que vive a experiência tensa da democracia." Paulo Freire associava cidadania e autonomia. Em seu último livro, ele afirma: "o respeito à autonomia e à dignidade de cada um é um imperativo ético e não um favor que podemos ou não conceder uns aos outros" ${ }^{3}$.

Tanto em sua concepção quanto em suas práticas, a escola cidadã se traduz por diferentes nomes e características próprias. Pode-se falar até em "tendências" diversas de escola cidadã. E isso é natural, uma vez que não podemos separar 
(4) AZEVEDO, José Clóvis de; GENTILI, Pablo; KRUG Andréa e SIMON, Cátia. Utopia e democracia na educação cidadã. Porto Alegre: Editora UFRGS, 2000

(5) GADOTTI, Moacir; ROMÃO, José Eustáquio (Orgs.). Autonomia da escola: Princípios e propostas. São Paulo: Cortez, 1997 (Série "Guia da Escola Cidadã" do Instituto Paulo Freire). "cidadania" de "autonomia". Sob muitos nomes encontramos a educação cidadã: Escola Pública Popular (São Paulo), Escola Democrática (Betim, MG), Escola Plural (Belo Horizonte), Escola Candanga (Brasília, DF), Escola Mínima (Gravataí, RS), Escola sem Fronteiras (Blumenau, SC), Escola Guaicurú (estado do Mato Grosso do Sul), Escola Democrática e Popular (estado do Rio Grande do Sul), Escola de Tempo Integral (Colatina, ES), Escola Desafio (Ipatinga, MG). O que importa não é o nome, mas a prática de uma escola honesta, séria, amiga, companheira, com uma nova qualidade, uma escola que atenda às necessidades da criança, do jovem e do adulto, da comunidade, apontando para o "bem viver", isto é, para uma vida mais saudável, produtiva, sustentável e feliz.

Um dos projetos pioneiros de escola cidadã e que continua até hoje é o de Porto Alegre (RS). Nesta cidade, desde a primeira gestão democrática-popular, iniciada em 1993, a escola cidadã compreende, principalmente, o planejamento participativo, a autonomia da escola como estratégia da qualidade de ensino e a construção da cidadania como prática pedagógica4 ${ }^{4}$.

Com outro nome, entre 1993 e 1996, o município de Belo Horizonte (MG) desenvolveu a experiência da Escola Plural, a qual tem servido de subsídio para muitos municípios elaborarem sua política educacional para uma educação para e pela cidadania. A Escola Plural, em uma perspectiva cidadã, levou esse nome por construir a política educacional do município, a partir da pluralidade de experiências emergentes na rede municipal de educação.

Em outros municípios e estados, a idéia da escola cidadã traduziu-se por características próprias locais, como em Gravataí (RS), onde, desde 1997, a Secretaria Municipal de Educação desencadeou um rico processo de reorientação curricular e formação continuada do magistério, resgatando suas raízes populares. O mesmo aconteceu em dois municípios próximos: Viamão e Alvorada. Em Caxias do Sul (RS), da mesma forma, a Secretaria de Educação mobilizou toda a cidade para a construção da participação e da democracia em um movimento cívico pelo orçamento participativo na educação. Baseada em Paulo Freire, entendeu a avaliação como redefinição conjunta dos caminhos a serem trilhados pelos cidadãos.

Experiências semelhantes vêm acontecendo desde final da década de 90 em municípios como os de Chapecó e Dionísio Cerqueira, no estado de Santa Catarina; Mauá, Diadema, Santo André e Franca, no estado de São Paulo; Icapuí, no estado do Ceará; em Goiânia, no estado de Goiás; em Natal, no Estado do Rio Grande do Norte; em Belém, no estado com Pará, com a chamada Escola Cabana, entre outros. O grande desafio desses projetos tem sido a descontinuidade administrativa dos governos municipais. Daí a insistência de muitos educadores na autonomia da escola ${ }^{5}$, fortalecendo o projeto político-pedagógico da unidade escolar.

Em duas gestões, desde 1993, a Secretaria de Educação de Uberaba (MG) desenvolveu um belo projeto com base nos princípios da escola cidadã, inicialmente orientado pelo próprio Paulo Freire. Uberaba entendeu a escola 
(6) A expressão "escola cidadã" que apareceu pela primeira vez na literatura pedagógica brasileira em um artigo de Genuino Bordignon, em maio de 1989, na Revista Educação Municipal, editada pela UNDIME (União Nacional de Dirigentes Municipais de Educação) e pela Editora Cortez, como uma "utopia municipalista". cidadã como uma "construção amorosa da cidadania" e deu uma contribuição nova ao projeto, associando conhecimento, sensibilidade e sustentabilidade. Como queria Paulo Freire: uma escola "séria, curiosa, questionadora, crítica, criativa e, sobretudo, alegre e prazerosa".

Em Blumenau (SC), a partir de 1977, o governo municipal vem trabalhando com o conceito de "Escola sem fronteiras - construindo cidadania pela educação", uma proposta esboçada um ano antes pelo sindicato da categoria, compreendendo "a gestão democrática, a qualidade social da educação e o acesso, permanência e sucesso de todos (as) os (as) educandos (as)", "ressignificando" as experiências da rede.

Em 1999 o estado do Rio Grande do Sul lançou um grande movimento pela construção da "Escola democrática e popular" por meio da "Constituinte Escolar" com base na metodologia de Paulo Freire e os seguintes pressupostos: a educação como um direito de todos os cidadãos e cidadãs; a participação popular enquanto método de gestão das políticas públicas; a dialogicidade enquanto princípio ético-existencial de um projeto humanista e solidário; a radicalização da democracia enquanto objetivo estratégico de um governo de esquerda; e a utopia enquanto sonho impulsionador da educação e da escola.

Espera-se que o estado do Rio Grande do Sul, ao lado do estado de Minas Gerais, com sua Escola Sagarana, e do Mato Grosso do Sul, com sua Escola Guaicuru, avancem em nível estadual, com a proposta alternativa ao neoliberalismo de uma educação para e pela cidadania. A escola cidadã está deixando de ser uma "utopia municipalista", como dizia, em 1989, Genuíno Bordignon $^{6}$, para se transformar também, dez anos depois, em utopia "estadual" (esperamos que um dia ela possa transformar-se em projeto "nacional").

Esses são apenas alguns exemplos, entre tantos, para ilustrar esse rico e variado movimento educacional, associado a uma concepção pedagógica cada vez mais consolidada, que temos chamado de "concepção dialética da educação", seguindo os caminhos da pedagogia da práxis. Todos esses exemplos, direta ou indiretamente, inspiram-se no pensamento de Paulo Freire, o que mostra sua atualidade e força transformadora. Alguns de seus princípios pedagógicos ou de intuições originais de sua prática são facilmente encontrados nessas experiências de educação cidadã, fundadas em relações eminentemente democráticas. Eis alguns desses princípios: 1) partir das necessidades dos alunos e das comunidades; 2) instituir uma relação dialógica professor-aluno; 3) considerar a educação como produção e não como transmissão e acumulação de conhecimentos; 4) educar para a liberdade e para a autonomia; 5) respeito à diversidade cultural; 6) defender a educação como um ato de diálogo no descobrimento rigoroso, porém, por sua vez, imaginativo, da razão de ser das coisas; 7) o planejamento comunitário e participativo.

A escola cidadã, inicialmente muito centrada na democratização da gestão e no planejamento participativo, aos poucos ampliou suas preocupações para a 
(7) Esses encontros foram organizados pelo Instituto Paulo Freire e coordenados por Paulo Roberto Padilha, diretor pedagógico do Instituto Paulo Freire e José Clóvis de Azevedo, ex-secretário de educação de Porto Alegre. Dezenas de relatos I34 de experiências práticas de "Escolas Cidadãs" puderam ser debatidos nesses encontros.

(8) ROMÃO, José Eustáquio. Dialética da diferença: O projeto da escola cidadã frente ao projeto pedagógico neoliberal. São Paulo: Cortez, 1998

(9) AZEVEDO, José Clóvis de. Escola cidadã: Desafios, diálogos e travessias. Petrópolis: Vozes, 2000, p. 47

(10) O Primeiro Congresso Internacional das Cidades Educadoras teve lugar na cidade de Barcelona, em novembro de 1990, no qual foi aprovada uma carta de princípios básicos que devem formar o perfil educativo da cidade. Cinco cidades brasileiras são membros da Associação Internacional de Cidades Educadoras: Belo Horizonte (MG), Caxias do Sul (RS), Cuiabá (MT), Pilar (PB) e Porto Alegre (RS). construção de um novo currículo (interdisciplinar, transdisciplinar, intercultural) e de relações sociais, humanas e intersubjetivas novas, enfrentando os graves problemas gerados pelo aumento da violência e da deterioração da qualidade de vida nas cidades e no campo.

Uma década de inovação e de experimentação, com base em uma concepção cidadã da educação, foi suficiente para gerar um grande movimento, uma perspectiva concreta de futuro para a escola pública, demonstrando que a sociedade civil está reagindo à tendência oficial neoliberal, a um modelo de internacionalização da agenda da educação, que segue a mesma "receita" contida em "recomendações" de organismos internacionais, como o Banco Mundial e o FMI.

Em outubro de 2001, durante a realização do Fórum Mundial de Educação, o Instituto Paulo Freire coordenou o Primeiro Encontro Nacional das Escolas Cidadãs e, durante o Fórum Social Mundial, em fevereiro de 2002, também coordenou um Primeiro Encontro Internacional de Escolas Cidadãs ${ }^{7}$. Tenho a firme convicção que o Movimento pela Escola Cidadã, nascido no final do século 20 , terá um forte impacto na educação na primeira metade do século 21 , similar ao Movimento pela Escola Nova, nascido no final do século 19, de grande impacto no século 20. O Movimento da Escola Nova se opunha à educação tradicional, assim como, hoje, o Movimento da Escola Cidadã se opõe à educação neoliberal8. A escola cidadã é o contraponto da "mercoescola", organizada "dentro da lógica empresarial voltada às necessidades de mercado" 9 .

O que tem a ver o Movimento da Escola Cidadã com o Movimento das Cidades Educadoras, iniciado na mesma época? ${ }^{10}$. Foi novamente Porto Alegre integrando desde o ano 2001 o Movimento das Cidades Educadoras - que deu a partida, iniciando uma nova caminhada nessa associação, como podemos constatar durante a ralização do X Seminário Nacional de Educação, realizado em Porto Alegre, de 13 a 15 de maio de 2002, com o tema geral: Culturas e ciclos da vida: desafios da (re) invenção da escola na cidade educadora. É a cidade como espaço de cultura educando a escola e a escola como palco do espetáculo da vida educando a cidade.

A cidade dispõe de inúmeras possibilidades educadoras. A vivência na cidade constitui um espaço cultural de aprendizagem permanente por si só. Mas a cidade pode ser "intencionalmente" educadora. Uma cidade pode ser considerada como uma cidade educadora quando, além de suas funções tradicionais - econômica, social, política e de prestação de serviços -, ela exerça uma nova função cujo objetivo é a formação para e pela cidadania. Para uma cidade ser considerada educadora, ela precisa promover e desenvolver o protagonismo de todos - crianças, jovens, adultos, idosos - na busca de um novo direito, o direito à cidade educadora.

Na cidade educadora todos os seus habitantes usufruem das mesmas oportunidades de formação, desenvolvimento pessoal e entretenimento que a 
(11) MOLL, Jaqueline. Os desafios contemporâneos da educação pública: compromissos da Secretaria Municipal de Educação de Porto Alegre. Revista Paixão de aprender, Porto Alegre: SMED, n. 14 , p. 25 , nov. 2001.

(12) GENRO, Tarso. O novo espaço público: 21 teses para a criação de uma política democrática e socialista. Folha de $S$. Paulo, 9 jun. 1996 Cadernos Mais. cidade oferece. O Manifesto das cidades escolas, aprovado em Barcelona, em 1990, e revisto em Bolonha, em 1994, afirma: "a satisfação das necessidades das crianças e dos jovens, no âmbito das competências do município, pressupõe uma oferta de espaços, equipamentos e serviços adequados ao desenvolvimento social, moral e cultural, a serem partilhados com outras gerações. O município, no processo de tomada de decisões, deverá levar em conta o impacto das mesmas. A cidade oferecerá aos pais uma formação que Ihes permita ajudar os seus filhos a crescer e utilizar a cidade num espírito de respeito mútuo. Todos os habitantes da cidade têm o direito de refletir e participar na criação de programas educativos e culturais, e a dispor dos instrumentos necessários que Ihes permitam descobrir um projeto educativo, na estrutura e na gestão da sua cidade, nos valores que esta fomenta, na qualidade de vida que oferece, nas festas que organiza, nas campanhas que prepara, no interesse que manifeste por eles e na forma de os escutar".

Nesse contexto, o conceito de escola cidadã ganha um novo componente: a comunidade educadora reconquista a escola no novo espaço cultural da cidade, integrando-a a esse espaço, considerando suas ruas e praças, árvores, pássaros, cinemas, bibliotecas, bens e serviços, bares e restaurantes, teatros e igrejas, empresas e lojas... enfim, toda a vida que pulsa na cidade. A escola deixa de ser um lugar abstrato para se inserir definitivamente na vida da cidade e ganhar, com isso, nova vida. A escola se transforma em um novo território de construção da cidadania.

Podemos falar de escola cidadã e de cidade educadora quando existe diálogo entre a escola e a cidade. Não se pode falar de escola cidadã sem compreendê-la como escola participativa, apropriada pela população como parte da apropriação da cidade a que pertence. Nesse sentido, escola cidadã, em maior ou menor grau, supõe a existência de uma cidade educadora. Essa apropriação acontece por mecanismos criados pela própria escola, como o colegiado escolar, a constituinte escolar, plenárias pedagógicas e outros. Esse ato de sujeito da própria cidade leva para dentro da escola os interesses e necessidades da população. Esse é o "cenário" da cidade educadora, como diz Jaqueline Moll, no qual as práticas escolares possibilitem qualificar o "entendimento freireano da leitura da palavra escrita como leitura do mundo e, portanto, como compreensão analítica e reflexiva dos problemas cotidianos e desafios postos pela contemporaneidade"11.

Tarso Genro ${ }^{12}$, por duas vezes prefeito de Porto Alegre, destaca, entre suas “... 21 teses para a criação de uma política democrática e socialista”, a necessidade de uma "nova cultura política, mais abrangente, de disputa hegemônica e de incorporação de novos agentes sociais" e uma "nova esfera pública com organizações locais, regionais, nacionais e internacionais, autoorganizadas", rompendo a distância entre Estado e cidadania. A cidade educadora é, na verdade, a realização dos objetivos do próprio planejamento urbano, a saber: a "promoção e a melhoria das condições de hábitat viabilizando 
(13) CARVALHO, Pompeu Figueiredo de. In: BRAGA, Roberto; CARVALHO, Pompeu Figueiredo de (Orgs.). Estatuto da cidade: Política urbana e cidadania. Rio Claro: Unesp, 2000, p. 42.

(14) BAVA, Sílvio Caccia. A reapropriação das cidades. Cadernos le monde diplomatique. Porto Alegre: Fórum Sociais Mundial, p. 18, 2001.

(15) Foi, em Edgar Faure, em seu relatório preparado para a Unesco, no Ano Internacional da Educação (1970), publicado em 1972 com o título Apprendre a Être, que aparece pela primeira vez a expressão "cidade educativa", referindo-se a um processo de

"compenetração íntima" entre educação e "vida cívica". Fiz uma análise crítica desse relatório em minha tese de doutorado em ciências da educação, defendida na Universidade de Genebra (Suíça), em 1997, e publicada em 1981 pela Editora Paz e Terra, de São Paulo, com o título A educação contra a educação. Em 1979, o professor da PUC de São Paulo, Jefferson Ildefonso da Silva, publica sua tese de mestrado com o título Cidade educativa: Um modelo de renovação da educação (São Paulo: Cortez \& Moraes) sobre o mesmo tema. uma vida saudável, social, material e espiritualmente (cultura, educação e trabalho) para todos os munícipes... maior eficácia social e maior eficiência econômica do capital social, ou seja, do ambiente construído que é a cidade, distribuindo-se igualitariamente ou eqüitativamente os benefícios e o ônus dos investimentos urbanos, na perspectiva da busca da sociedade sustentável"13.

Quando podemos falar em cidade educadora?

Podemos falar em cidade educadora quando ela busca instaurar, com todas suas energias, a cidadania plena, ativa, quando ela mesma estabelece canais permanentes de participação, incentiva a organização das comunidades para que elas tomem em suas mãos, de forma organizada, o controle social da cidade. É a sociedade controlando o Estado e o mercado. A cidade educadora persegue a utopia das cidades justas, produtivas, democráticas e sustentáveis - aquelas que conseguem "romper com o controle político das elites locais e com as formas burocráticas, corruptas e clientelistas de governar" 14 e estabelecem uma nova esfera pública de decisão não-estatal, como o "orçamento participativo" e a "constituinte escolar", já emblemáticos nas gestões populares. Saímos das propostas nesse campo e novas experiências vêm surgindo em diferentes partes do país, levadas a cabo por diferentes partidos políticos, com novas relações, novas formas de gestão, novos espaços de negociação, estimulando a reapropriação das cidades por seus cidadãos. E não há segredo nisso. Basta vontade política, apoiada em uma ética a qual condene o segredo burocrático com a transparência, que incorpore o conflito com práticas de negociação e publicize a informação.

E qual é o papel da escola nesse contexto?

O papel da escola (cidadã), nesse contexto, é contribuir para criar as condições que viabilizem a cidadania, por meio da socialização da informação, da discussão, da transparência, gerando uma nova mentalidade, uma nova cultura, em relação ao caráter público do espaço da cidade.

Há uma concepção neoliberal da cidade que a considera apenas como um mercado. Nesse caso, a pedagogia neoliberal objetiva formar consumidores para o mercado. Há uma concepção emancipadora da cidade, que já foi defendida até em relatório da Unesco ${ }^{15}$, a qual entende a cidade como espaço formativo. Para essa concepção, o papel da escola é formar cidadãos.

Em uma perspectiva transformadora, a escola educa para ouvir e respeitar as diferenças, a diversidade que compõe a cidade e que constitui sua grande riqueza. O cidadão da cidade educadora presta atenção ao diferente e também ao "deficiente", ou melhor, ao portador de direitos especiais. Para que a escola seja espaço de vida, e não de morte, ela precisa estar aberta para a diversidade cultural, étnica e de gênero e às diferentes opções sexuais. As diferenças exigem uma nova escola.

O grande desafio da escola em uma cidade educativa é traduzir esses princípios em experiências práticas inovadoras, em projetos para a capacitação 
(16) DOWBOR, Ladislau. A reprodução social: Propostas para uma gestão descentralizada. Petrópolis: Vozes, 1998.

(17) SANTOS, Milton. O professor como intelectual na sociedade contemporânea. In: IX ENDIPE - ENCONTRO NACIONAL DE DIDÁTICA E PRÁTICA DE ENSINO, 1999. São Paulo. Anais... São Paulo, vol. III, 1999, p. 14 cidadã da população, para que ela possa tomar em suas mãos os destinos de sua cidade. Diante dos novos espaços de formação, criados pela sociedade da informação, ela os integra e articula. Deixa de ser "lecionadora" para ser cada vez mais "gestora" da informação generalizada ${ }^{16}$, construtora e reconstrutora de saberes e conhecimentos socialmente significativos. Portanto, ela tem um papel mais articulador da cultura, um papel mais dirigente e agregador de pessoas, movimentos, organizações e instituições. Na sociedade do conhecimento, o papel social da escola foi consideravelmente ampliado. É uma escola presente na cidade e cria conhecimento, sem abrir mão do conhecimento historicamente produzido pela humanidade, uma escola científica e transformadora.

A cidade, sobretudo a grande metrópole, está chegando aos limites do suportável (violência, estresse, desemprego, falta de habitação, de transporte, de saneamento...) e não tem outra alternativa, hoje, a não ser se transformar, radicalmente, em "novas cidades", em cidades educadoras. Caso contrário, as cidades estarão caminhando rapidamente para se transformarem em espaços de extermínio, sobretudo dos jovens. A educação e a cultura não podem tudo, porque existem outros componentes - os sociais, políticos e, sobretudo, econômicos. Mas ela pode contribuir para a construção de uma sociedade saudável, tornando-se amiga e "companheira", como dizia Paulo Freire, transformando-se em um espaço de formação ético-política de pessoas que se querem bem e, por isso, têm legitimidade para transformar a vida da cidade.

Qual é o papel do professor da escola cidadã na cidade educadora?

A cidade violenta e insustentável insere-nos em um clima de medo e de falta de esperança. Nossa força como educadores é limitada. Nossas escolas são também produto da sociedade. Contudo, a esperança, para o professor, para a professora, não é algo vazio, de quem espera acontecer. Ao contrário, a esperança para o professor encontra sentido em sua própria missão, a de transformar pessoas, dar nova forma às pessoas, e alimentar, por sua vez, a esperança das mesmas para que consigam construir uma realidade diferente, uma cidade nova, "mais humana, menos feia, menos malvada", como costumava dizer Paulo Freire. Uma educação sem esperança não é educação.

Educação, nessa nova cidade, confunde-se com o próprio processo de humanização. Respondendo à questão "como o professor pode tornar um intelectual na sociedade contemporânea", o grande geógrafo brasileiro Milton Santos, falecido no ano de 2001, respondeu: "Quando consideramos a história possível e não apenas a história existente, passamos a acreditar que outro mundo é viável. E não há intelectual que trabalhe sem idéia de futuro. Para ser digno do homem, qual seja, do homem visto como projeto, o trabalho intelectual e educacional tem que ser fundado no futuro. É dessa forma que os professores podem tornar-se intelectuais: olhando o futuro." 17

O professor precisa indagar-se, constantemente, sobre o sentido do que está fazendo. Se isso é fundamental para todo ser humano, como ser que busca 
(18) VASCONCELLOS, Celso. Para onde vai o professor? Resgate do professor como sujeito de transformação. São Paulo: Libertad, 2001, p. 51-52.

(19) Idem, p. 55.

(20) DOWBOR, Ladislau. Tecnologias do conhecimento: Os desafios da educação. Petrópolis: Vozes, 2001 , p. 79-80. sentido o tempo todo, para o professor é também um dever profissional. Faz parte de sua competência profissional continuar indagando, com seus colegas e alunos, sobre o sentido do que estão fazendo na escola. Ele está sempre em processo de construção de sentido. Como diz Celso Vasconcellos ${ }^{18}$, "o sentido não está pronto em algum lugar esperando ser descoberto. O sentido não advém de uma esfera transcendente, nem da imanência do objeto ou ainda de um simples jogo lógicoformal. É uma construção do sujeito!" Celso Vasconcellos, ex-aluno de Paulo Freire, insiste, em seu belo livro, que o papel do professor é "educar através do ensino" 19 . Ele pode apenas ensinar tabuada, mas só educa pelo ensino quando construir o sentido da tabuada com seu aprendiz, por que, como diz ele, ensinar vem do latim insignare, que significa "marcar com um sinal", atuar na construção do significado do que fazemos. Tudo o que fazemos precisa ser feito com sentido, tudo o que estudamos tem de ter sentido.

Os dois maiores educadores do século passado, John Dewey e Paulo Freire, cada um a seu modo, procuraram responder a essa questão e centraram suas análises na relação entre "educação e vida", reagindo às pedagogias tecnicistas de seu tempo - tanto de esquerda quanto de direita - que só se preocupavam com métodos e técnicas. "Gostaria de ser lembrando como alguém que amou a vida", disse Paulo Freire duas semanas antes de falecer. A educação só tem sentido como vida. Ela é vida. A escola perde seu sentido de humanização quando a educação vira mercadoria, quando deixa de ser o lugar onde a gente aprende a ser gente, para se tornar o lugar onde as crianças e os jovens vão para aprender a competir no mercado.

É preciso mostrar que o neoliberalismo, com sua política de mercantilização da educação, tornou essa profissão descartável. É preciso mostrar também que o projeto político neoliberal capitalista inviabiliza uma educação de qualidade para todos.

É sintomático como Ladislau Dowbor finaliza seu livro Tecnologias do conhecimento ${ }^{20}$, com dados de um Relatório das Nações Unidas, de 1998, para mostrar o descaso, a indiferença e o cinismo do neoliberalismo quanto às necessidades das pessoas: "Não se consegue os 6 bilhões de dólares que seriam necessários para colocar nas escolas quem está fora delas, no planeta; tampouco se conseguem os 9 bilhões para assegurar água e saneamento para todos, ou os 13 bilhões necessários para assegurar saúde básica e nutrição para todos. Mas, se conseguem 8 bilhões para cosméticos nos Estados Unidos, 11 bilhões para sorvete na Europa, 17 bilhões de ração para animais de estimação, 50 bilhões para cigarros na Europa, 400 bilhões para narcóticos e 780 bilhões para gastos militares no mundo." Onde estão as prioridades do mundo? O relatório das Nações Unidas nem precisa responder.

Por isso é preciso fazer a análise crítica, social, econômica. Mas tudo isso não basta. É preciso que a rigorosa análise da situação não fique nela, mas aponte caminhos e indique-nos como caminhar. Caso contrário, as análises 
sociológicas e políticas, por mais rigorosas e corretas que sejam, ajudam apenas para manter o imobilismo e a falta de perspectivas para a educação.

0 poder do professor está tanto em sua capacidade de refletir, criticamente, sobre a realidade para transformá-la quanto na possibilidade de formar um grupo de companheiros e companheiras. Paulo Freire insistia que a escola transformadora era a "escola de companheirismo"; por isso, sua pedagogia é uma pedagogia do diálogo, das trocas, do encontro, das redes solidárias. "Companheiro" vem do latim e significa "aquele que partilha o pão". Trata-se, portanto, de uma postura radical, ao mesmo tempo crítica e solidária. Às vezes, somos apenas críticos e perdemos o afeto dos outros por falta de companheirismo. E não haverá superação das condições atuais do magistério sem um profundo sentimento de companheirismo. Lutando sozinhos chegaremos apenas à frustração, ao desânimo, à lamúria. Daí o sentido profundamente ético dessa profissão. No fundo, para enfrentar a barbárie neoliberal na educação, vale ainda a tese de Marx - "o próprio educador deve ser educado", educado para a construção histórica de um sentido novo de seu papel.

Florestan Fernandes costumava repetir que a escola não educava para a cidadania. Ele dizia que a estrutura de poder no Brasil era arcaica e mantida pela classe dominante, que barrava a consciência crítica do povo. Essa estrutura político-social e econômica ainda é dominante. Mas a mesma sociedade que cria essa estrutura, cria também sua reação. A contradição social existe. Por isso, encontramos motivos para ser otimistas. Um deles é o surgimento da escola cidadã e da cidade educadora. Elas não têm apenas a mesma identidade do ponto de vista etimológico. Elas apontam para o mesmo projeto de futuro, para a construção de uma sociedade educadora-educanda, humanizada, emancipada e solidária.

\section{Moacir Gadotti}

Doutor em ciências da educação pela Universidade de Genebra (Suíça), professor titular da Universidade de São Paulo, diretor do Instituto Paulo Freire e autor, entre outras obras, de: A educação contra a educação (Paz e Terra, 1979 - francês e português), Convite à leitura de Paulo Freire (Scipione, 1988 - português, espanhol, inglês, japonês e italiano), História das idéias pedagógicas (Ática, 1993 - português e espanhol), Pedagogia da práxis (Cortez, 1994 - português, espanhol e inglês) e Perspectivas atuais da educação (Artes Médicas, 2000 - português e espanhol), Pedagogia da terra (Peirópolis, 2001 - português e espanhol) e Um legado de esperança (Cortez, 2001). 